\title{
Perancangan Aplikasi Ensiklopedia Ilmuwan Islam Berbasis Android dengan Metode Crochemore Perrin
}

\author{
Fitria \\ Program Studi Teknik Informatika, STMIK Budi Darma, Medan, Indonesia \\ Email:Ria85000@gmail.com
}

\begin{abstract}
Abstrak-Ensiklopedia berupa sejumlah tulisan yang berisi penjelasan yang menyimpan informasi secara komprehensif dan cepat dipahami dan di mengerti. Ilmuwan secara umum berarti kepandaian dan pengetahuan dengan bidang yang tersusun secara sistematis menurut kaidah dan metode yang bisa digunakan untuk menerangkan dan menjelaskan serta hal yang memahami yang terkait dengan bidang ilmuwan tersebut. Salah satu solusi untuk menyelesaikan permasalahan pencarian ilmuwan islam berbasis Android dengan metode Crochemore Perrin. Untuk mempermudah proses pencarian string pada ensiklopedia ilmuwan islam berbasis Android. Dengan diterapkan algoritma crochemore perrin pada sistem pencarian ilmuwan islam berbasis Android maka dengan melakukan proses pencarian ilmuwan islam lebih mudah dan cepat. Sistem yang dirancang sangat praktis karna menggunakan aplikasi Android. Sehingga dapat diakses dimana saja.
\end{abstract}

Kata Kunci: Ensiklopedia, Ilmuwan Islam, Android, Crochemore- Perrin

Abstract- Encyclopedia in the form of a number of writings that contain explanations that store information comprehensively and quickly understood and understood. Scientists generally mean intelligence and knowledge in a field arranged systematically according to the rules and methods that can be used to explain and explain and understand things related to the field of scientists. One solution to solve the problem of searching for Android-based Islamic scientists with the Crochemore Perrin method. To simplify the process of searching strings on Android-based Islamic scientist encyclopedias. By applying the Perrin Crochemore algorithm to the Android-based Islamic scientist search system, the process of searching for Islamic scientists is easier and faster. The system is designed very practical because it uses an Android application. So it can be accessed anywhere.

Keywords: Encyclopedia, Islamic Scientist, Android, Crochemore-Perrin

\section{PENDAHULUAN}

Ensiklopedia adalah sejumlah tulisan yang berisi penjelasan yang menyimpan informasi secara komprehensif dan capat dipahami serta dimengerti mengenai seluruh cabang ilmu pengetahuan atau khusus dalam satu cabang pengetahuan tertentu yang tersusun dalam bagian artikel-artikel dengan satu topik bahasa pada tiap-tiap artikel yang disusun menjadi abjad, kategori atau volume terbitan dan pada umumnya tercetak dalam bentuk rangkaian buku. Ilmuwan secara umum berarti kepandaian dan pengetahuan dengan bidang yang tersusun secara sistematis menurut kaidah dan metode yang bisa digunakan untuk menerangkan dan menjelaskan serta memahami hal yang terkait dengan bidang ilmu tersebut.

Saat ini tidak dapat dipungkiri bahwa perkembangan ilmu pengetahuan sekarang sangat dipengaruhi oleh para ilmuwan. Banyak ilmuwan terkemuka di muka bumi ini memberikan kontribusi lebih dalam memajukan perkembangan ilmu pengetahuan dan teknologi. Mereka banyak ditemukan dalam buku sejarah ilmu pengetahuan, enslikopedi, dan buku pengetahuan lainnya. Hal ini membuat siswa-siswi utamanya sekolah dasar sudah mengenal para ilmuan seperti Alexander Graham Bell penemu pesawat telepon, Aristoteles, Galileo Galilei dan banyak lainnya.

Fenomena kurang mengenal ilmuan muslim ini membuat kalangan cendikiawan muslim mulai memperkenalkan ilmuan-ilmuan muslim dalam buku ajar pendidikan agama islam di pendidikan formal. Upaya ini sebagai wujud terobosan bagi kalangan tokoh-tokoh islam membuat suatu penanaman kembali tentang penemu muslim yang mampu menjadi acuan ilmuan nasrani menemukan hasil karyanya seperti pesawat terbang, ahli bedah dan lainnya. Sebelumnya ilmuan muslim seperti Abbas Qasim Ibnu Firnas penemu konsep dasar pesawat Siswasiswi dan bahka mahasiswa banyak yang tidak mengenal ilmuan muslim.

Algoritma crochemore- Perrin atau sering disebut dengan algoritma Two Way Algorithm, atau Algoritma Dua Arah. Algoritma ini memfaktorkan pattern menjadi dua bagian Pattren $n_{\text {kiri }}$, dan pattern $_{\text {kanan }}$ sehingga pattern=pattern kiri pattern $_{\text {kanan. }}$. Fase pencocokan pada algoritma ini terdiri dari dua bagian, pertama mencocokan karakter $p^{a t t e r n} n_{\text {kanan }}$ dari kiri kekanan, lalu mencocokan karakter pattern $n_{\text {kir }}$ dari kanan ke kiri [1].

Proses pencarian string atau sering disebut juga dengan pencocokan string (string matching atau pattern matching) telah menjadi kebutuhan dalam pemrosesan teks. Algoritma string digunakan untuk mencari satu atau lebih string (disebut pattern) dalam kumpulan dalam string lain (teks). Persoalan pencarian string dapat dibagi dalam beberapa langkah. Pertama, diberikan teks yaitu srting yang panjangnya $n$ karakter. Kemudain, diberikan pattern yaitu string dengan panjang $\mathrm{m}$ karakter $(\mathrm{m}<\mathrm{n})$ yang akan dicari dalam teks.

penulis menggunakan algoritma crochemore perrin berdasarkan dari penelitian sebelumnya yang pernah dilakukan oleh "Boby Halim Lukman" dengan judul "Penerapan Algoritma Crochemore Perrin Pada Pencarian Jurnal Berbasis Mobile". Dimana algoritma ini sebagai solusi untuk melakukan pencarian terhadap pattern yang dijadikan sebagai acuan untuk menghasilkan sauatu apliksi pencarian jurnal dengan mudah. Penelitian sebelumnya juga pernah dilakukan oleh "Dany Breslauer" dengan judul "Saving Comparisons In The Crochemore Perrin 
AKON Volume 1, No. 1, September 2019

ISSN 2685-998X (Media Online)

DOI: 10.30865/json.v1i1.1364

String Matching Algorithm". Dimana algoritma ini juga dapat berjalan dengan baik pada saat digunakan untuk menyimpan ruang konstanta waktu linier dengan baik. Adapun solusi untuk permasalahan tersebut penulis menyimpulkan bahwa algoritma crochemore perrin cocok untuk diterapkan sebuah aplikasi pencarian ilmuwan Islam.

Oleh karena itu penulis tertarik untuk menganalisa penggunaan metode Crochemore-Perrin karena menggunakan pencarian dari dua arah.

\section{METODE PENELITIAN}

\subsection{Ensiklopedia}

Ensiklopedia berasal dari bahasa Yunani Encylospadea merupakan himpunan fakta yang dilakukan secara berseri atau disiplin ilmu yang diuraikan secara informatif dan komprehensif. Dalam bahasa Yunani, kata "encyklos" berarti "umum", sedangkan kata "pedia" berarti "pendidikan". Dalam bahasa Inggris, sering ditulis "Encyclopaedia", "Cyclopedia", dan "Cyclopedia" yang artinya pendidikan umum [2].

\subsection{Ilmuwan Islam}

Ilmuwan merupakan hasil karya seseorang yang dikomunikasikan dan dikaji secara luas oleh masyarakat. Jika hasil karyanya itu memenuhi syarat-syarat keilmuwan, maka karya ilmiah itu, akan menjadi ilmu pengetahuan dan digunakan oleh masyarakat luas. Ilmuwan memiliki tanggung jawab yang besar, ilmuwan tidak hanya sebatas penelitian bidang keilmuwan, tetapi juga tanggung jawab atas hasil penelitiannya agar dapat digunakan masyarakat, serta tanggung jawab dalam mengawal hasil penelitian agar tidak di salah gunakan [3].

\subsection{Algoritma Crochemore Perrin}

Algoritma Crochemore-Perrin, yang sering juga disebut algoritma Two Way Algoritma, atau Algoritma Dua Arah dipublikasikan Maxime Crochemore dan Dominique Perrin pada tahun 1991 [4]. Algoritma ini memfaktorkan bagian menjadi dua bagian bagian kiri dan bagian kanan sehingga bagian= bagian kiri bagian kanan. Face pencocokan pada algortima ini terdiri dari dua bagian, pertama mencocokkan karakter bagian kanan dari kiri kekanan, lalu mencocokkan karakter bagian kiri dari kanan ke kiri. Fase inisialisasi pada algortima ini menghitung faktorisasi yang baik dari bagian atas bagian kiri dan bagian kanan. Jika (u.v) merupakan sebuah faktorisasi dari bagian, maka sebuah pengulangan di (u.v) adalah sebuah kata w, sehingga dua buah persyaratan ini terpenuhi.

1. $\mathrm{w}$ adalah akhiran dari $\mathrm{u}$ atau $\mathrm{u}$ adalah akhiran dari $\mathrm{w}$

2. w adalah awalan dari $\mathrm{v}$ atau $\mathrm{v}$ adalah awalan dari $\mathrm{w}$

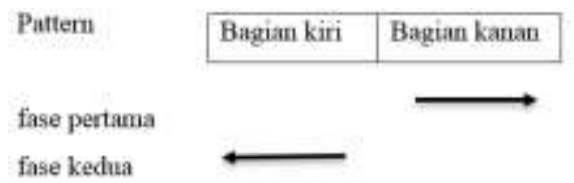

Gambar 1. Pembagian Pattern Pada Algoritma Crochemore-Perrin

Algortima Crochemore-Perrin memiliki faktorisasi kritis (bagian kiri, bagian kanan) sehingga |bagian kiri $\mid<$ per (x) dan |bagian kini| mempunyai nilai minimal. Dengan kata lain, kata w muncul di kedua sisi dari potongan $\mathrm{u}$ dan v dengan kemungkinan overflow di kedua sisi. Panjang dari pegulangan terkecil di (u,v). Setiap faktorisasi dari ( $\mathrm{u}, \mathrm{v})$ paling tidak mempunyai satu pengulangan. Dapat dilihat dengan mudah bahwa $1 \mathrm{r}(\mathrm{u}, \mathrm{v})|\mathrm{x}|$. Faktorisasi $(\mathrm{u}, \mathrm{v})$ dari $\mathrm{x}$ sehingga $\mathrm{r}(\mathrm{u}, \mathrm{v})=\operatorname{per}(\mathrm{x})$ disebut dari faktorisasi kritis dari $\mathrm{x}$, maka pada posisi pada $|\mathrm{u}|$ di $\mathrm{x}$, periode lokal dan periode global akan sama [4].

Dalam algoritma String Matching pencarian String secara umum dirumuskan sebagi berikut:

1. Sebuah teks (text), yaitu sebuah long string yang panjang $\mathrm{n}$ karakater

2. Bagian, yaitu sebuah string dengan panjang $m$ dan karakater $(\mathrm{m}<\mathrm{n})$ yang akan dicari dalam text.

Dalam algoritma pencocokan string, teks di asumsikan kedalam memori, sehingga bila ingin mencari string di dalam sebuah arsip, maka semua isi arsip perlu dibaca terlebih dahulu kemudian disimpan didalam memori. Jika bagian muncul lebih dari sekali didalam teks, maka pencarian hanya akan memberikan keluaran berupa lokasi bagian ditemukan pertama kali.

Algoritma yang digunakan dalam melakukan pencocokan string (string matching) yaitu algoritma string matching Crochemore-Perrin. Berikut ini adalah cara kerja Crochemore-Perrin sebagai berikut:

1. Langkah pertama Crochrmore-Perrin dimulai dengan menentukan bagian paling kanan dan bagian paling kiri, sebagai teks acuan pencarian.

2. Algoritma ini akan mencocokan teks dengan bagian berdasarkan bagian kanan dan periode: 
a. Jika karakter sesuai dengan bagian kanan, diberi tanda sebagai periode awal, dan lanjut ke karakter selanjutnya, kemudia proses awal pencarian selanjutnya dimulai dari periode terakhir.

b. Jika tidak sesuai geser karakter satu persatu dan kembali kelangkah (a) [1].

\section{ANALISA DAN PEMBAHASAN}

Analisa dapat dilakukan sebagai suatu proses untuk menentukan suatu masalah ilmuwan Islam. Karna banyaknya seorang pelajar yang kurang mengenal tentang ilmuwan muslim ini membuat kalangan muslim ingin memperkenalkan tentang ilmuwan muslim ke pada seorang pelajar terutamanya bagi sekolah dasar pastinya mereka tidak mengenal sama sekali tentang ilmuwan Islam maka dari itu penulis ingin mempermudah bagi seorang pelajar mengenal tentang ilmuwan islam ini melalui ensiklopedia ilmuwan Islam agar lebih mudah dimengerti dan dipahami tentang ilmuwan Islam. Ilmuwan Islam dalam bentuk buku yang akan dijadikan penulis menjadi suatu aplikasi dengan sistem operasi Android. Dengan adanya aplikasi ini akan mepermudah seorang pelajar mengetahui ilmuwan Islam.

Pada proses pencarian ilmuwan Islam akan dirancang dengan menggunakan algoritma crochemore perrin. Dalam algoritma pencarian string termasuk algoritma crochemore perrin terdapat teks dan pattern. Dimana dalam proses pencarian ilmuwan Islam sebagai kunci pencarian, apabila ada kecocokan maka hasil temuwan yang dicari akan tampil, namun apabila proses dalam pencarian tidak ditemukan maka masukan judul ataupun kata kunci yang ingin dicari pencarian pada kolom pencarian. Langkah pertama dari cara kerja algoritma crochemore perrin dimulai dari menemtukan pattren $_{\text {kanan }}$ dan pattren $_{\text {kiri }}$ sebagai teks acuan pencarian, algoritma ini akan mencocokan teks dengan pattren berdasarkan pattren $_{\text {kanan }}$ dan periode, jika karakter sesuai dengan pattren $_{\text {kanan }}$, beri tanda sebagai periode awal, dan lanjutkan ke karakter selanjutnya, kemudia proses awal selanjutnya dimulai dari periode terakhir, namun jika tidak sesuai geser karakter satu persatu dan kembali ke langkah awal.

Pencarian ilmuwan Islam berbasis Android menggunakan bahasa pemrograman Java dengan platform yang digunakan adalah Eclipse Jono. Eclipse merupakan sebuah IDE (Integrated Development Environment) untuk menggembangkan perangkat lunak dan dapat dijalankan di semua platform (platform-independent). Eclipse membutuhkan Android SDK (Software Developmen Kit) windows sebagain alat bantu dan API (Application Programming Interface) dalam mengembangkan aplikasi pada platform Android menggunakan bahasa pemrograman Java. Berikut ini adalah beberapa hasil temuwan dan nama penemuwan

Tabel 1. Nama Ilmuwan Dan Hasil Temuwan

\begin{tabular}{lll}
\hline No & Hasil Temuwan & Nama Penemuwan \\
\hline 1. & Penemu Dibidang Astronomi & $\begin{array}{l}\text { Nama lengkap Al-Kindi adalah Abu Yusuf } \\
\text { bin Ishaq bin Ash-Shabah bin Imran bin Al- } \\
\text { Asy'ats bin Qais. }\end{array}$ \\
& & $\begin{array}{l}\text { Abu Al-Hasan bin Marwan Tsabit bin Qurah } \\
\text { Al-Harrani. }\end{array}$ \\
2. & Penemu Dibidang Matematika & Abu Bakar Muhammad bin Zakariya Ar-Razi \\
& & Abu Ali Al-Husin bin Abdullah bin Sina. Dia \\
3. & Penemu Dibidang Kimia & dikenal dengan gelar”Asy-Syaikh Ar-Ra'is “ \\
4. & Penemu Dibidang Kedokteran &
\end{tabular}

Berikut penerapan algoritma crochemore perrin :

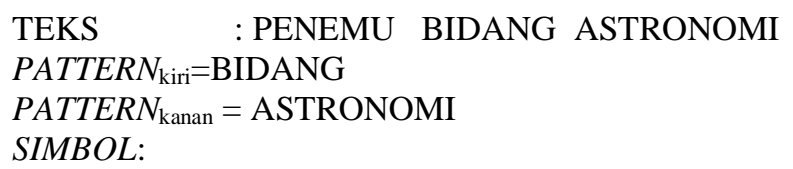

Penyelesaian :

Langkah pertama mencocokan pattern kanan dengan teks yang akan dicari

\begin{tabular}{|l|l|l|l|l|l|l|l|l|l|l|l|l|l|l|l|l|l|l|l|l|l|l|l|}
\hline $\mathrm{T}$ & $\mathrm{P}$ & $\mathrm{E}$ & $\mathrm{N}$ & $\mathrm{E}$ & $\mathrm{M}$ & $\mathrm{U}$ & & $\mathrm{B}$ & $\mathrm{I}$ & $\mathrm{D}$ & $\mathrm{A}$ & $\mathrm{N}$ & $\mathrm{G}$ & & $\mathrm{A}$ & $\mathrm{S}$ & $\mathrm{T}$ & $\mathrm{R}$ & $\mathrm{O}$ & $\mathrm{N}$ & $\mathrm{O}$ & $\mathrm{M}$ & $\mathrm{I}$ \\
\hline $\mathrm{P}$ & & & & & & & & 1 & & & & & & & & & & & & & & & \\
\hline $\mathrm{X}$ & $\mathrm{B}$ & $\mathrm{I}$ & $\mathrm{D}$ & $\mathrm{A}$ & $\mathrm{N}$ & $\mathrm{G}$ & & $\mathrm{A}$ & $\mathrm{S}$ & $\mathrm{T}$ & $\mathrm{R}$ & $\mathrm{O}$ & $\mathrm{N}$ & $\mathrm{O}$ & $\mathrm{M}$ & $\mathrm{I}$ & & & & & & & \\
\hline
\end{tabular}

Karna karakter 1 pada pattern dengan teks tidak sesuai, maka geser pattern awal sebanyak satu karakter kekanan.

\begin{tabular}{|l|l|l|l|l|l|l|l|l|l|l|l|l|l|l|l|l|l|l|l|l|l|l|l|}
\hline $\mathrm{T}$ & $\mathrm{P}$ & $\mathrm{E}$ & $\mathrm{N}$ & $\mathrm{E}$ & $\mathrm{M}$ & $\mathrm{U}$ & & $\mathrm{B}$ & $\mathrm{I}$ & $\mathrm{D}$ & $\mathrm{A}$ & $\mathrm{N}$ & $\mathrm{G}$ & & $\mathrm{A}$ & $\mathrm{S}$ & $\mathrm{T}$ & $\mathrm{R}$ & $\mathrm{O}$ & $\mathrm{N}$ & $\mathrm{O}$ & $\mathrm{M}$ & $\mathrm{I}$ \\
\hline $\mathrm{P}$ & & & & & & & & & 1 & & & & & & & & & & & & & & \\
\hline $\mathrm{X}$ & & $\mathrm{B}$ & $\mathrm{I}$ & $\mathrm{D}$ & $\mathrm{A}$ & $\mathrm{N}$ & $\mathrm{G}$ & & $\mathrm{A}$ & $\mathrm{S}$ & $\mathrm{T}$ & $\mathrm{R}$ & $\mathrm{O}$ & $\mathrm{N}$ & $\mathrm{O}$ & $\mathrm{M}$ & $\mathrm{I}$ & & & & & & \\
\hline
\end{tabular}

Karna karakter 1 pada pattern dengan teks tidak sesuai, maka geser pattern awal sebanyak satu karakter kekanan. 


\begin{tabular}{|l|l|l|l|l|l|l|l|l|l|l|l|l|l|l|l|l|l|l|l|l|l|l|l|}
\hline $\mathrm{T}$ & $\mathrm{P}$ & $\mathrm{E}$ & $\mathrm{N}$ & $\mathrm{E}$ & $\mathrm{M}$ & $\mathrm{U}$ & & $\mathrm{B}$ & $\mathrm{I}$ & $\mathrm{D}$ & $\mathrm{A}$ & $\mathrm{N}$ & $\mathrm{G}$ & & $\mathrm{A}$ & $\mathrm{S}$ & $\mathrm{T}$ & $\mathrm{R}$ & $\mathrm{O}$ & $\mathrm{N}$ & $\mathrm{O}$ & $\mathrm{M}$ & $\mathrm{I}$ \\
\hline $\mathrm{P}$ & & & & & & & & & & 1 & & & & & & & & & & & & & \\
\hline $\mathrm{X}$ & & & $\mathrm{B}$ & $\mathrm{I}$ & $\mathrm{D}$ & $\mathrm{A}$ & $\mathrm{N}$ & $\mathrm{G}$ & & $\mathrm{A}$ & $\mathrm{S}$ & $\mathrm{T}$ & $\mathrm{R}$ & $\mathrm{O}$ & $\mathrm{N}$ & $\mathrm{O}$ & $\mathrm{M}$ & $\mathrm{I}$ & & & & & \\
\hline
\end{tabular}

Karna karakter 1 pada pattern dengan teks tidak sesuai, maka geser pattern awal sebanyak satu karakter kekanan.

\begin{tabular}{|l|l|l|l|l|l|l|l|l|l|l|l|l|l|l|l|l|l|l|l|l|l|l|l|}
\hline $\mathrm{T}$ & $\mathrm{P}$ & $\mathrm{E}$ & $\mathrm{N}$ & $\mathrm{E}$ & $\mathrm{M}$ & $\mathrm{U}$ & & $\mathrm{B}$ & $\mathrm{I}$ & $\mathrm{D}$ & $\mathrm{A}$ & $\mathrm{N}$ & $\mathrm{G}$ & & $\mathrm{A}$ & $\mathrm{S}$ & $\mathrm{T}$ & $\mathrm{R}$ & $\mathrm{O}$ & $\mathrm{N}$ & $\mathrm{O}$ & $\mathrm{M}$ & $\mathrm{I}$ \\
\hline $\mathrm{P}$ & & & & & & & & & & & 1 & & & & & & & & & & & & \\
\hline $\mathrm{X}$ & & & & $\mathrm{B}$ & $\mathrm{I}$ & $\mathrm{D}$ & $\mathrm{A}$ & $\mathrm{N}$ & $\mathrm{G}$ & & $\mathrm{A}$ & $\mathrm{S}$ & $\mathrm{T}$ & $\mathrm{R}$ & $\mathrm{O}$ & $\mathrm{N}$ & $\mathrm{O}$ & $\mathrm{M}$ & $\mathrm{I}$ & & & & \\
\hline
\end{tabular}

Karna karakter 1 pada pattern dengan teks tidak sesuai, maka geser pattern awal sebanyak satu karakter kekanan.

\begin{tabular}{|l|l|l|l|l|l|l|l|l|l|l|l|l|l|l|l|l|l|l|l|l|l|l|l|}
\hline $\mathrm{T}$ & $\mathrm{P}$ & $\mathrm{E}$ & $\mathrm{N}$ & $\mathrm{E}$ & $\mathrm{M}$ & $\mathrm{U}$ & & $\mathrm{B}$ & $\mathrm{I}$ & $\mathrm{D}$ & $\mathrm{A}$ & $\mathrm{N}$ & $\mathrm{G}$ & & $\mathrm{A}$ & $\mathrm{S}$ & $\mathrm{T}$ & $\mathrm{R}$ & $\mathrm{O}$ & $\mathrm{N}$ & $\mathrm{O}$ & $\mathrm{M}$ & $\mathrm{I}$ \\
\hline $\mathrm{P}$ & & & & & & & & & & & & 1 & & & & & & & & & & & \\
\hline $\mathrm{X}$ & & & & & $\mathrm{B}$ & $\mathrm{I}$ & $\mathrm{D}$ & $\mathrm{A}$ & $\mathrm{N}$ & $\mathrm{G}$ & & $\mathrm{A}$ & $\mathrm{S}$ & $\mathrm{T}$ & $\mathrm{R}$ & $\mathrm{O}$ & $\mathrm{N}$ & $\mathrm{O}$ & $\mathrm{M}$ & $\mathrm{I}$ & & & \\
\hline
\end{tabular}

Karna karakter 1 pada pattern dengan teks tidak sesuai, maka geser pattern awal sebanyak satu karakter kekanan.

\begin{tabular}{|l|l|l|l|l|l|l|l|l|l|l|l|l|l|l|l|l|l|l|l|l|l|l|l|}
\hline $\mathrm{T}$ & $\mathrm{P}$ & $\mathrm{E}$ & $\mathrm{N}$ & $\mathrm{E}$ & $\mathrm{M}$ & $\mathrm{U}$ & & $\mathrm{B}$ & $\mathrm{I}$ & $\mathrm{D}$ & $\mathrm{A}$ & $\mathrm{N}$ & $\mathrm{G}$ & & $\mathrm{A}$ & $\mathrm{S}$ & $\mathrm{T}$ & $\mathrm{R}$ & $\mathrm{O}$ & $\mathrm{N}$ & $\mathrm{O}$ & $\mathrm{M}$ & $\mathrm{I}$ \\
\hline $\mathrm{P}$ & & & & & & & & & & & & & 1 & & & & & & & & & & \\
\hline $\mathrm{X}$ & & & & & & $\mathrm{B}$ & $\mathrm{I}$ & $\mathrm{D}$ & $\mathrm{A}$ & $\mathrm{N}$ & $\mathrm{G}$ & & $\mathrm{A}$ & $\mathrm{S}$ & $\mathrm{T}$ & $\mathrm{R}$ & $\mathrm{O}$ & $\mathrm{N}$ & $\mathrm{O}$ & $\mathrm{M}$ & $\mathrm{I}$ & & \\
\hline
\end{tabular}

Karna karakter 1 pada pattern dengan teks tidak sesuai, maka geser pattern awal sebanyak satu karakter kekanan.

\begin{tabular}{|l|l|l|l|l|l|l|l|l|l|l|l|l|l|l|l|l|l|l|l|l|l|l|l|}
\hline $\mathrm{T}$ & $\mathrm{P}$ & $\mathrm{E}$ & $\mathrm{N}$ & $\mathrm{E}$ & $\mathrm{M}$ & $\mathrm{U}$ & & $\mathrm{B}$ & $\mathrm{I}$ & $\mathrm{D}$ & $\mathrm{A}$ & $\mathrm{N}$ & $\mathrm{G}$ & & $\mathrm{A}$ & $\mathrm{S}$ & $\mathrm{T}$ & $\mathrm{R}$ & $\mathrm{O}$ & $\mathrm{N}$ & $\mathrm{O}$ & $\mathrm{M}$ & $\mathrm{I}$ \\
\hline $\mathrm{P}$ & & & & & & & & & & & & & & 1 & & & & & & & & & \\
\hline $\mathrm{X}$ & & & & & & & $\mathrm{B}$ & $\mathrm{I}$ & $\mathrm{D}$ & $\mathrm{A}$ & $\mathrm{N}$ & $\mathrm{G}$ & & $\mathrm{A}$ & $\mathrm{S}$ & $\mathrm{T}$ & $\mathrm{R}$ & $\mathrm{O}$ & $\mathrm{N}$ & $\mathrm{O}$ & $\mathrm{M}$ & $\mathrm{I}$ & \\
\hline
\end{tabular}

Karna karakter 1 pada pattern dengan teks tidak sesuai, maka geser pattern awal sebanyak satu karakter kekanan.

\begin{tabular}{|l|l|l|l|l|l|l|l|l|l|l|l|l|l|l|l|l|l|l|l|l|l|l|l|}
\hline $\mathrm{T}$ & $\mathrm{P}$ & $\mathrm{E}$ & $\mathrm{N}$ & $\mathrm{E}$ & $\mathrm{M}$ & $\mathrm{U}$ & & $\mathrm{B}$ & $\mathrm{I}$ & $\mathrm{D}$ & $\mathrm{A}$ & $\mathrm{N}$ & $\mathrm{G}$ & & $\mathrm{A}$ & $\mathrm{S}$ & $\mathrm{T}$ & $\mathrm{R}$ & $\mathrm{O}$ & $\mathrm{N}$ & $\mathrm{O}$ & $\mathrm{M}$ & $\mathrm{I}$ \\
\hline $\mathrm{X}$ & & & & & & & & & & & & & & & & & & & & & & & \\
\hline $\mathrm{P}$ & & & & & & & & $\mathrm{B}$ & $\mathrm{I}$ & $\mathrm{D}$ & $\mathrm{A}$ & $\mathrm{N}$ & $\mathrm{G}$ & & $\mathrm{A}$ & $\mathrm{S}$ & $\mathrm{T}$ & $\mathrm{R}$ & $\mathrm{O}$ & $\mathrm{N}$ & $\mathrm{O}$ & $\mathrm{M}$ & $\mathrm{I}$ \\
\hline
\end{tabular}

Pattern ditemukan, karna setiap pattern dan teks selesai.

\section{KESIMPULAN}

Berdasarkan hasil analisa, maka penulis dapat menarik kesimpulan, yaitu:

1. Proses pencarian ilmuwan Islam akan dirancang menggunakan algoritma crochemore perrin. Dalam algoritma pencarian string termasuk algoritma crochemore perrin terdapat teks dan pattern. Pencarian ilmuwan Islam sebagai kata kunci pencarian, apabila ada kecocokan maka hasil temuwan yang dicari akan tampil, namun apabila proses dalam pencarian tidak ditemukan maka masukan judul atau kata kunci yang ingin dicari pencarian pada kolom pencarian.

2. Aplikasi ensiklopedia ilmuwan Islam dirancang dengan menggunakan eclipse sebagai editor dan SDK (Software Developmen Kit) sebagai alat pengembang aplikasi pada platform Android menggunakan bahasa pemrograman Java.

3. Algoritma crochemore perrin dapat diimplementasikan dalam pencarian aplikasi ensiklopedia ilmuwan Islam berbasis Android, dapat memudaahkan dalam pencaarian berdasarkan pattern.

\section{REFERENCES}

[1] Boby Halim Lukman, "Penerapan Algoritma Crochemore Perrin Pada Pencarian Jurnal Berbasis Mobile," peneliti Inform., vol. 17, pp. 37-42, 2018.

[2] dalam A. berliantin S. . Anne, pengembangan ensiklopedia berbasis joyful learning. Yogyakarta: UIN Sun Kalijaga, 2014.

[3] R. Abkari, 101 Info Tentang Ilmuwan Muslim. Bandung: PT. Mizan Pustaka, 2010.

[4] M. Suyanto, ANALISA DAN DESAIN APLIKASI MULTIMEDIA UNTUK PEMASARAN. Andi, 2004. 